\title{
O DIREITO DE INTERVENÇÃO NO ÂMBITO DAS RELAÇÕES INTERNACIONAIS: A JUSTIFICAÇÃO RACIONAL SEGUNDO A FILOSOFIA POLÍTICA DE JOHN RAWLS
}

\section{Lucas Romero Montenegro}

Graduando em Direito pela Universidade Federal do Ceará e membro do Grupo de Pesquisa em Filosofia dos Direitos Humanos lucas_lrm@hotmail.com

Sumário: Introdução. 1. Aspectos da utopia realista. 2. O direito de intervenção segundo o direito dos povos. 3. A unidade da razão em Kant segundo a interpretação de Rawls. 4. A filosofia política de Rawls como defesa da fé razoável. Conclusão. Referências.

Resumo: A soberania, enquanto qualidade do poder estatal, tem sido questionada em nome de normas internacionais de justiça. Nesse contexto, o direito de intervenção, possivelmente pautado em tais normas, surge então como forma de adequar determinadas sociedades a padrões políticos e sociais preponderantes. Este trabalho visa, então, a compreender de que forma John Rawls justifica racionalmente o direito de intervenção, entendido como o direito de implementar padrões sociais e políticos mínimos, mesmo partindo-se de uma concepção liberal de justiça política.

Palavras-chave: John Rawls. Direito de intervenção. Justificação racional.

\section{INTRODUÇÃO}

Pode-se dizer, com Catherine Audard, que a atual discussão quanto a normas internacionais de justiça oscila, muitas vezes, entre polos opostos de uma visão "essencialista" e acrítica dos direitos humanos, pautada num rol de direitos positivados que se acredita serem inerentes a todo homem, e a visão que sustenta serem tais normas "a pura e simples expressão de um imperialismo cultural e político, um instrumento de controle e dominação de populações em escala global, segundo um modelo colonizador ampliado." (AUDARD, 2005, p. 23, tradução nossa).

No centro do debate, como forma de composição dessas visões extremas, a ideia de justificação racional desempenha papel fundamental: confere 
universalidade às normas internacionais de justiça, buscando superar não só as acusações de que são normas infundadas e vazias de sentido, mas o argumento relativista, que as veem como estratégia política e ideológica imperialista.

O trabalho visa, então, a investigar de que forma Rawls, à luz de seu Direito dos Povos, e do fato do pluralismo por ele reconhecido, fundamenta o direito de intervenção sobre o que chama de sociedades oneradas por condições desfavoráveis, para as quais se tem também um dever de assistência, bem como sobre os chamados Estados fora-da-lei, caracterizados por agir sempre de modo a satisfazer seus interesses particulares.

Dividir-se-á o desenvolvimento do trabalho em quatro tópicos, sendo que o primeiro deles tratará do que Rawls entende ser uma utopia realista, uma proposta tendente à cooperação, à estabilidade e à paz no âmbito internacional. A seguir, será exposto seu direito de intervenção sobre as sociedades acima referidas, como uma forma de transição para a Sociedade de Povos bem-ordenados.

Passa-se, então, a abordar a interpretação que Rawls faz da unidade da razão em Kant, de fundamental importância para esclarecer sua própria fundamentação acerca do direito de intervenção. Por fim, abordar-se-á a defesa da fé razoável como o papel da filosofia política, o que, segundo acreditamos, consiste na razão pela qual Rawls legitima um direito de intervenção nos termos da sua proposta de Direito dos Povos.

A metodologia do trabalho é de caráter bibliográfico, tendo sido feita a leitura das obras de John Rawls, sempre que possível no original, quando tivemos acesso às obras em inglês, bem como de alguns de seus comentadores e de parte da obra de Kant que julgamos necessária ao trabalho.

\section{Aspectos da Utopia Realista}

Em O Direito dos Povos, Rawls intenta demonstrar a razoabilidade de seu Direito dos Povos, isto é, uma concepção política particular de direito e justiça aplicada a princípios e normas do direito e da prática internacionais" (RAWLS, 2002, p. 3, tradução nossa). Essa concepção de justiça cumpre o papel de reger a cooperação entre povos liberais e decentes, com base na ideia de foedus pacificum, conforme o caminho sugerido por Kant ${ }^{1}$.

\footnotetext{
Kant apresenta essa ideia em sua obra Para a Paz Perpétua: "E, não obstante, a razão, desde o trono do máximo poder legislativo moral, condena a guerra como uma vida jurídica e converte, em troca, em um dever imediato o estado de paz, que não pode estabelecer-se ou garantir-se, certamente, sem um pacto entre os povos: há de existir, portanto, uma federação de tipo especial a que se possa chamar federação da paz (foedus pacificum), que se distinguiria do pacto de paz (pactum pacis), já que este buscaria acabar com uma guerra e a outra buscaria terminar com todas as guerras para sempre.” (KANT, 2006, p. 75-76)
} 
Está preocupado, do início ao fim do trabalho, em demonstrar quais as condições de uma tal utopia realista, que venha finalmente celebrar a paz e a cooperação entre povos:

Eu começo e termino com a ideia de uma utopia realista. Filosofia política é realisticamente utópica quando estende o que é normalmente entendido como os limites da possibilidade da prática política. (RAWLS, 2002, p. 6-7, tradução nossa)

Assim, o que pretende Rawls é, com base nas razões por ele apresentadas, fazer-nos acreditar, aproveitando-se exatamente do fato de que os tais limites da possibilidade não são claros, que a prática política permite uma reconciliação com o que seria nossa real condição política e social.

Para que seja considerada realista, a proposta precisa atender a duas condições. A primeira delas é a de que o Direito dos Povos funcione e possa ser aplicado às relações políticas entre os povos. Segundo, impõe-se, para que se conceba uma Sociedade de Povos, na qual os povos sejam vistos tais como eles são, isto é, como organizados em uma sociedade liberal e justa, conforme Rawls sugere em seus escritos anteriores, e o Direito dos Povos como ele seria em uma Sociedade de Povos razoável e justa, fazendo referência à famosa frase de Rousseau.

Nesse ponto, é interessante ressaltar a opção que se faz pela expressão "povos", em vez da tradicional "Estados". A concepção tradicional de Estado integra o que chama de os dois poderes tradicionais de soberania: o direito de ir à guerra para perseguir seus interesses racionais, bem como uma certa autonomia no que se refere ao seu próprio povo. Compreende-se, assim, a denominação "Estados fora-da-lei", isto é, aqueles Estados que ainda arrogam a si os tais poderes de soberania, mesmo em face da mudança radical no plano das relações internacionais.

Os Estados são tidos por agentes puramente racionais, no sentido que Rawls dá ao termo², de modo que utilizam sua força militar, econômica e diplomática com intuito exclusivo de satisfazer seus interesses básicos:

A visão típica das relações internacionais é fundamentalmente a mesma dos dias de Tucídides e não foi superada nos tempos modernos, quando o mundo político é ainda marcado pelos esforços dos estados por poder, prestígio e riqueza, numa condição anarquia global. Estados diferem de povos tanto quanto a racionalidade, a preocupação com poder e o e os interesses básicos daqueles são preenchidos. (RAWLS, 2002, p. 28, tradução nossa)

\footnotetext{
"O conceito de racionalidade invocado aqui, com exceção de uma característica essencial, é um padrão familiar em teoria social. Assim, no sentido usual, uma pessoa racional é compreendida como tendo um conjunto de preferências entre as opções abertas para ela. Ela classifica essas opções de acordo com as quais perseguem melhor seus propósitos; ela segue o plano que satisfaça mais seus desejos e que tenha uma grande chance de sucesso.” (RAWLS, 1999, p. 123-124, tradução nossa)
} 
O termo "povos" é utilizado, por conseguinte, para enfatizar características que os Estados tradicionalmente não têm e que são caras para a construção de um Direito dos Povos justo e estável. Ressalta-se, como principal característica dos povos liberais, o fato de serem povos detentores de um caráter moral, ou seja, razoáveis e racionais, assim como Rawls concebe os cidadãos no interior de uma sociedade liberal e democrática.

No âmbito interno, para que se possa conceber a sociedade como um sistema equitativo de cooperação, que Rawls chama de ideia organizadora fundamental em $O$ Liberalismo Político, é necessário compreender cidadãos como agentes, ao mesmo tempo, razoáveis e racionais, pois a cooperação equitativa depende de uma disposição para propor termos "que cada participante pode razoavelmente aceitar, desde que todos os outros aceitem" (RAWLS, 2000, p. 58-59), bem como "requer uma ideia de vantagem racional ou do bem de cada participante." (RAWLS, 2000, p. 59).

Igualmente, a cooperação entre povos liberais depende de que estes sejam concebidos não só como racionais, mas também como seres razoáveis, capazes de oferecer termos de cooperação que acreditam que todos possam aceitar. Implica, com isso, o critério de reciprocidade entre povos iguais e livres, que precisam ser satisfeitos pelos princípios e regras que regerão o Direito dos Povos:

Os princípios dessas concepções de justiça devem também satisfazer ao critério de reciprocidade. Esse critério exige que, quando termos são propostos como os termos de cooperação equitativa mais razoáveis, aqueles que os propõem devem pensar que é razoável que outros os aceitem como cidadãos livres e iguais, e não como dominados ou manipulados sob pressão causada por uma posição social ou política inferior. (RAWLS, 2002, p. 14, tradução nossa)

Assim caracterizados, os povos estão aptos a eleger, assim como Ralws sustenta também no âmbito interno das sociedades, a ideia de posição original como um artifício de representação, a ser utilizado pelos povos no processo de construção do conteúdo da concepção política que regerá suas relações.

A posição original funciona como um modelo de representação, na qual cada povo imagina um representante incumbido da tarefa de responder pelos interesses daquele povo junto aos demais representantes de outros povos, num processo de decisão acerca dos princípios de justiça política que regerão o direito e a prática internacionais. Essa discussão se faz sob o chamado "véu da ignorância", de modo que os representantes não têm conhecimento sobre o tamanho do território, a riqueza, tamanho da população, poderio militar, recursos naturais e outros aspectos relativos ao seu povo e aos demais.

$\mathrm{O}$ véu da ignorância garante a simetria entres os contratantes e limita a discussão a argumentos razoáveis, pois são levados a propor termos 
de cooperação que acreditam todos possam aceitar, e não aqueles termos que favoreceriam determinados povos em face de suas circunstâncias (poder econômico e militar, grande quantidade de recursos naturais etc.), uma vez que não têm qualquer informação sobre sua própria posição.

A discussão, na posição original, deve girar apenas entre as diferentes formulações e interpretações dos oito princípios a seguir: (i) os povos são livres e independentes, e sua liberdade e independência devem ser respeitados pelos outros povos; (ii) os povos devem observar os tratados e acordos; (iii) os povos são iguais em partes nos acordos que os vinculam; (iv) os povos devem observar o dever de não intervenção; ; (v) os povos têm o direito de auto-defesa, mas não têm o direito de instigar outras razões; (vi) os povos devem honrar os direitos humanos ${ }^{4}$; (vii) os povos devem observar determinadas restrições à conduta durante a guerra; e (viii) os povos têm o dever de assistir outros povos que vivem sob condições desfavoráveis que os impedem de ter um regime social e político justo ou decente.

Nesse sentido, estão em consonância com as limitações aos tradicionais poderes de soberania e com o que Rawls chama de interesses fundamentais dos povos, assim entendidos:

Assim, eles empenham-se em proteger sua independência política e sua cultura livre com suas liberdades civis, em garantir sua segurança, seu território; aplicado aos povos, isso se enquadra no que Rousseau chamou de amour-propre. Esse interesse é o respeito de um povo enquanto tal, residindo na consciência comum de seus caminhos na história e das conquistas de sua cultura. Completamente diversa da preocupação com sua segurança e a de seu território, esse interesse mostra-se na insistência de um povo em receber de outros o respeito devido e o reconhecimento de sua igualdade. (RAWLS, 2002, p. 34, tradução nossa)

Por fim, cumpre mencionar a exigência de tolerância ${ }^{5}$ para com povos não liberais, bem como a extensão do Direito dos Povos para os chamados "povos hierárquicos decentes". Para Ralws, são povos caracterizados por não possuírem fins agressivos, embora possuam assumidamente uma visão abrangente (religiosa, filosófica ou moral) que influencia a estrutura governamental e sua política social. Exige-se também que seu sistema legal seja regido por uma ideia de bem comum e respeite os direitos humanos, entendidos nos termos restritos

Ressalvados, claro, os casos dos Estados fora-da-lei e as sociedades oneradas por condições desfavoráveis.

4 Rawls propõe uma concepção restrita de direitos humanos, objeto inclusive de muitas críticas, que envolve basicamente o direito à vida, liberdade, propriedade pessoal e igualdade formal.

5 Rawls adota sentido amplo para o termo tolerância, que significa um reconhecimento enquanto participantes iguais de um sistema de cooperação. Não há sentido de negação ou condenação, pois não seria liberal considerar inaceitável outras formas decentes de ordenar uma sociedade. 
já aduzidos, bem como impõe à sua população deveres e obrigações derivados dessa ideia de bem comum.

Interessante registrar três argumentos principais nos quais, segundo Catherine Audard (AUDARD, 2007, p. 250-253), Rawls sustenta a tolerância dos povos decentes ${ }^{6}$. Primeiro, tem-se o respeito pelo direito de autodeterminação dos povos. A autora sustenta que o critério para se aferir como e se uma sociedade é democrática é um critério dinâmico, que envolve uma trajetória histórica de esforços e conquistas. Por isso, autorrespeito e um certo grau de autonomia são fundamentais para uma relação cooperativa e equitativa entre os povos.

Em segundo lugar, ressalta o fato do pluralismo razoável entre povos, visto que exigir uma democracia para todos os demais povos seria considerada uma atitude não liberal, arrogante e irrazoável. Rawls sustenta que um dos aspectos de uma pessoa razoável é o reconhecimento dos limites do juízo. Segundo esse aspecto, o desacordo entre pessoas razoáveis é inevitável, tendo em vista "os muitos acasos envolvidos no correto (e consciencioso) exercício de nossas faculdades de raciocínio e julgamento no curso normal da vida política". (RAWLS, 2000, p. 99).

O terceiro argumento é o de que a ideia de decência estabelece uma meta e um ponto limítrofe, a partir do qual é legítima uma intervenção humanitária:

\footnotetext{
Sustenta-se que os erros dos realistas e dos cosmopolitanistas só podem ser superados por "uma meta e um ponto limítrofe", a fim de atingir um balanço entre respeito pela autonomia e proteção de direitos humanos básicos das populações envolvidas. A especificidade das relações internacionais permite tratar povos como iguais dentro de alguns limites precisos, mesmo que internamente eles não tratem seus membros como iguais. (AUDARD, 2005, p. 252)
}

Muito mais haveria de ser dito acerca de sua utopia realista. No entanto, consideramos o esposado suficiente para os propósitos deste artigo, ressaltando ainda que, embora o tratemos em tópico apartado, o direito de intervenção é componente da utopia realista, enquanto integrante do que Rawls chama de teoria não ideal.

\section{Direito de Intervenção Segundo o Direito dos Povos}

Considerando as condições extremas de injustiça e desigualdade que vigoram no contexto internacional, Rawls considera imprescindível, antes de considerar completa sua ideia de Direito dos

6 A autora defende, todavia, que entender direitos humanos restritamente é "provavelmente um preço muito alto a pagar pela cooperação de povos não liberais." (AUDARD, 2007, p. 241, tradução nossa). 
Povos, abordar o problema de transição gradual daquelas sociedades que não querem ou podem satisfazer as prescrições das normas internacionais de justiça. Passa então a analisar o caso especial de dois tipos de sociedades: os Estados fora-da-lei e os povos onerados.

Os Estados fora-da-lei são caracterizados por Rawls como aqueles que se recusam a observar os princípios e regras do Direito dos Povos, agindo de acordo com seus interesses puramente racionais e acreditando que a satisfação destes é suficiente para entrar em guerra com outros povos. Nesse sentido, há casos em Estados como esses "violam direitos reconhecidos pela sociedade de povos razoáveis e decentes e estão sujeitos a algum tipo de intervenção em casos graves." (RAWLS, 2002, p. 90, tradução nossa).

E assim o entende porque concebe direitos humanos como sendo exigíveis universalmente, mesmo por aqueles Estados que não os reconhecem, mas não os podem desconsiderar com uma ideia supostamente ocidental. Assim, seria legítima uma intervenção em casos extremos de violação àqueles direitos:

A lista de direitos humanos honrados por povos liberais e regimes hierárquicos decentes deve ser entendida como direitos universais no seguinte sentido: eles são intrínsecos ao Direito dos Povos e têm um efeito político (e moral), independentemente de serem apoiados localmente. Isto é, sua força política (e moral) estende-se para todas as sociedades, e eles vinculam todos os povos e sociedades, incluindo os Estados fora-da-lei. (RAWLS, 2002, p. 80-81, tradução nossa)

Por outro lado, há também o caso das sociedades oneradas por condições desfavoráveis, isto é, sociedades que não são agressivas nem expansionistas, mas, em face das condições sociais, econômicas e políticas que atravessam, não conseguem garantir à sua população a satisfação de um mínimo social necessário para se integrarem à Sociedade de Povos.

Em tais casos, os povos liberais e decentes têm, para com essas sociedades, um direito de assistência. Pode-se falar, ao mesmo tempo, num direito de intervenção, no sentido de implementação de determinados princípios e regras, uma vez que o "fim a longo prazo é que sociedades (relativamente) bem-ordenadas devem trazer sociedades oneradas, bem como Estados fora-da-lei, para a Sociedade de Povos bem-ordenados." (RAWLS, 2002, p. 106, tradução nossa).

Recorrendo a um estudo feito por Amartya Sen, Rawls ressalta que a simples disponibilidade de fundos não é suficiente para socorrer as sociedades oneradas, pois as falhas da estrutura política e social não permitem o devido aproveitamento dos recursos financeiros. Impõe-se, assim, uma ênfase em direitos humanos, com vistas a alterar a estrutura política e social, tornando-a mais eficaz. 
Impõe-se, para ambos os casos de intervenção, uma espécie de guia de instruções a ser seguido pelos povos, sempre tendo como um fim a longo prazo fazer das sociedades sujeitas à intervenção integrantes da Sociedade de Povos, relacionado-se sob os princípios e normas do Direito dos Povos. Por isso, a conduta de guerra tem de observar os direitos humanos, não só porque estes vinculam a ação dos povos liberais e decentes, mas porque se busca "ensinar os soldados e civis inimigos o conteúdo daquele direito, exemplificado pelo tratamento que eles recebem." (RAWLS, 2002, p. 96, tradução nossa).

Assim também é com o dever de assistência, pois "respeitar os direitos humanos poderia também desencadear pressão popular dentro de uma sociedade onerada, no sentido de exigir o que a economia e a sociedade podem decentemente sustentar" (RAWLS, 2002, p. 109, tradução nossa).

A simples exposição da utopia realista de Rawls, todavia, não responde ainda à questão de por que seria legítimo aos povos liberais e decentes impor sua própria concepção política, bem como julgar os demais povos segundo seus parâmetros e critérios tirados de sua cultura política. Não se extrai também a razão pela qual o Direito do Povos deve dispor de validade objetiva e universal.

A fim de se concluir sobre o que supomos ser a reposta que Rawls oferece a tais questões, trataremos antes da interpretação que o autor faz do pensamento kantiano, quanto à unidade da razão e sua autoautenticação, o que consideramos passo necessário para que se compreenda a justificação racional do direito de intervenção de Rawls.

\section{A Unidade da Razão em Kant Segundo a Interpretação DE RAWLS}

Iniciamos com o que Rawls sustenta ser o abandono da tentativa de empreender uma dedução da lei moral por parte de Kant. Afirma que Kant esforçou-se, durante muito tempo, para derivar a lei moral da razão teórica, capaz de evidenciar razões pelas quais não só um ser racional necessariamente agiria conforme aprovado pelo juízo moral, mas também se sentisse compelido a agir de tal forma.

Sustenta que o reconhecimento dessa impossibilidade restaria expresso em diversas passagens da obra de Kant, pois este acabaria por concluir que a lei moral não poderia ser derivada de nossa experiência moral, uma vez que é uma lei a priori com respeito à razão prática empírica, bem como que não poderia mesmo ser derivada da ideia de liberdade, que, enquanto postulado da razão prática, não possui intuição intelectual. 
Com isso, abre-se caminho para a questão da autenticação da lei moral. Se para ela não há qualquer dedução, como ser considerada, em última análise, adequada por um ser racional? De igual forma, qual é a motivação que o indivíduo tem para agir em sua conformidade? A resposta para tanto começa a ser dada por Kant, já na Fundamentação da Metafísica dos Costumes:

Ora, é impossível pensar uma razão que com a sua própria consciência recebesse de qualquer outra parte uma outra direção a respeito dos seus juízos, pois que então o sujeito atribuiria a determinação da faculdade de julgar não à sua razão, mas a um impulso. Ela tem de considerar-se a si como autora dos seus princípios, independentemente de influências estranhas; por conseguinte, como razão prática ou como vontade de um ser racional, tem de considerar-se a si mesma como livre; isto é, a vontade desse ser só pode ser uma vontade própria sob a idéia da liberdade, e, portanto, é preciso atribuir, em sentido prático, uma tal vontade a todos os seres racionais. (KANT, 1980, p. 150).

A lei moral é autenticada pelo que Kant chama de "fato da razão" e, para aqueles que o reconhecem, pela própria liberdade que, com isso, adquire realidade objetiva. Assim, Rawls conclui afirmando que o fato da razão consiste no "fato de que, como seres razoáveis, temos consciência da lei moral como a lei que é para nós a lei dotada de suprema autoridade e sumamente reguladora, e de que em nosso pensamento e juízo morais comuns a reconhecemos como tal." (RAWLS, 2005, p. 298).

O fato da razão vem responder à pergunta acerca de como a razão prática pode determinar a nossa vontade. Assim sendo, aqueles que têm consciência da lei moral como supremamente reguladora concebem-se como livres, visto que a liberdade assume realidade objetiva, embora não se saiba como.

Decorre disso que o reconhecimento do postulado da liberdade é uma ampliação do nosso conhecimento, mas apenas sob o ponto de vista prático. Todavia, a ampliação de tal conhecimento requer um propósito a priori, que consistiria no objeto da lei moral, pois a razão prática, para ser capaz de dirigir a vontade, depende de uma base de motivação:

(...) nossa consciência da lei moral como supremamente obrigatória para nós deve ser tão profundamente enraizada em nossa pessoa como razoável e racional, que essa lei por si mesma, quando plenamente conhecida e compreendida, possa ser um motivo suficiente para agirmos segundo ela, sejam quais forem nossos desejos naturais. (RAWLS, 2005, p. 293).

A razão prática, então, tem de construir seu objeto a priori. Rawls considera que a leitura de Kant possibilita compreendê-lo de duas formas: como um reino dos fins e como a ideia de sumo bem. Declara, todavia, sua preferência 
pelo primeiro, aduzindo que a ideia de sumo bem não foi trabalhada por Kant de forma coerente dentro dos princípios e conceitos de seu pensamento, de modo que trataremos apenas do reino dos fins, o que será suficiente para este trabalho.

Enquanto objeto a priori da lei moral, o reino dos fins pressupõe um mundo inteligível, no qual pessoas agem sempre movidas por aquilo que se pode chamar de uma boa vontade, isto é, não motivando suas ações em desejos, inclinações, paixões etc.:

Chamo mundo moral, o mundo na medida em que está conforme a todas as leis morais (tal como pode sê-lo, segundo a liberdade dos seres racionais e tal como deve sê-lo, segundo as leis necessárias da moralidade). O mundo é assim pensado apenas como um mundo inteligível, pois nele se faz abstração de todas as condições (ou fins) da moralidade e mesmo de todos os obstáculos que esta possa encontrar (fraqueza ou corrupção da natureza humana). (KANT, 2001, p. 641).

Por outro lado, também enquanto objeto da lei moral, o reino dos fins consiste em um ideal realizável no mundo natural, embora nunca plenamente. Impõe-se como um ideal de moralidade autorrecompensadora, que cada um aja como deve. Trata-se, portanto, de um mundo em que a natureza é sujeita à vontade, e não o contrário.

Isso pressupõe, todavia, que o próprio mundo natural seja amoldável a tal mundo inteligível, o que leva Kant a sustentar, argumenta Rawls, que não basta a crença razoável na liberdade. Há que haver uma crença genérica de que a própria ordem da natureza e do mundo social comportam o desenvolvimento rumo a esse ideal:

Não é suficiente afirmar nossa liberdade e reconhecer a liberdade de todas as pessoas em virtude de suas faculdades da razão. Pois só podemos acreditar que um reino dos fins é possível no mundo se a ordem da natureza e as necessidades sociais não forem hostis a esse ideal. Pois, para tanto, o mundo deve conter forças e tendências que, a longo prazo, tendam a produzir ou ao menos sustentar um tal reino e a educar a humanidade para que promova esse fim. (RAWLS, 2005, p. 366).

Portanto, vinculada ao fato da razão, surge uma fé razoável, isto é, uma crença razoável de que a natureza e a ordem social não são avessas a um aprimoramento moral progressivo da humanidade, em direção a um reino dos fins. O papel que Kant atribui à filosofia seria o de promover uma defesa dessa fé razoável.

Embora não se possa apresentar prova da existência da liberdade, o fato de não existirem provas de sua impossibilidade é suficiente para que creiamos e façamos reivindicações legítimas nesse sentido. O que Rawls quer dizer com 
isso é que Kant confere a cada razão, teórica e prática, interesses próprios, que não se equilibram, somam, ou subtraem um ao outro. Suas reivindicações, baseadas nos respectivos interesses, são igualmente legítimas.

Assim, a autenticação da razão prática, por meio da realidade objetiva que se confere à liberdade, não pode ser negada pela razão teórica, que renuncia ao campo especulativo. Ao mesmo tempo, é interesse da razão teórica "regular o entendimento e unificar na mais alta unidade sistemática possível o conhecimento científico de baixo nível que ele proporciona (...)" (RAWLS, 2005 , p. 370). Isso faz com que seja ilegítimo também se aferir a realidade dos postulados, entre os quais a liberdade, a partir da razão prática empírica, que se serve de desejos e inclinações.

Com isso, a razão como um todo autentica a si mesma, na medida em que harmoniza plenamente as reivindicações de ambas as razões, teórica e prática, dentro de uma mesma estrutura. Nisso residiria a intenção de Kant ao fazer uma crítica da razão: estabelecer essa unidade.

\section{A Filosofia Política de Rawls como Defesa da Fé Razoável}

No fim de um de seus escritos, intitulado A Ideia de um Consenso Sobreposto, Rawls faz a seguinte afirmação:

Ao exibir a possibilidade de um consenso sobreposto numa sociedade com uma tradição democrática e confrontada com o fato do pluralismo, a filosofia política assume o papel que Kant deu à filosofia em geral: a defesa da fé razoável. Em nosso caso, torna-se a defesa da fé razoável na real possibilidade de um regime constitucional justo. (RAWLS, 2001, p. 448, tradução nossa)

A mesma afirmação é feita, em um momento posterior, em O Liberalismo Politico, em termos mais ou menos semelhantes (RAWLS, 2000, p. 219). No caso, Rawls responde a objeções levantadas a sua hipótese de um consenso sobreposto envolvendo as diferentes doutrinas abrangentes no interior de uma sociedade liberal e democrática. São questões que se ligam à própria possibilidade do liberalismo político como resposta à necessidade de justiça política e estabilidade.

Embora não o diga expressamente em $O$ Direito dos Povos, há razões mais do que suficientes para supormos que Rawls também ali assume ser esse o papel da filosofia política, isto é, a defesa da fé razoável, o que, para o autor, consiste na justificação de um direito de intervenção.

Não se trata, entretanto, de sustentar que Rawls assume integralmente o pensamento kantiano, tampouco de supor que a lei moral kantiana 
é sumamente reguladora, a ser, então, seguida pelos povos. O pensamento de Rawls, desde as alterações feitas na proposta original de Uma Teoria da Justiça, tem se pautado na elaboração de uma concepção de justiça política, que é dotada de autossuficiência, isto é, que não se baseia em nenhuma doutrina abrangente, seja religiosa, filosófica ou moral.

Assim, Rawls assume, também, como é imprescindível à própria ideia de fé razoável, a impossibilidade de se apresentar uma justificação plenamente convincente, cuja validade objetiva e universal é inquestionável:

\begin{abstract}
Alguns podem achar esse fato difícil de aceitar. Isso porque é frequentemente entendido que a tarefa da Filosofia é elaborar uma forma de argumento que se prove sempre convincente contra todos os outros argumentos. Tal argumento, entretanto, não existe. Os povos poderão sempre ter fins últimos que os levarão a opor-se uns aos outros sem qualquer compromisso. (RAWLS, 2002, p. 123, tradução nossa)
\end{abstract}

Isso porque os povos são autônomos, no sentido de que cabe a eles adotar os princípios de justiça do Direito dos Povos, como sendo aqueles que seus representantes formulariam na posição original. Com efeito, em sua proposta de Direito dos Povos, não há princípios ou conceitos deduzidos da razão prática. Ao contrário, ele dá conteúdo à razão prática através das ideias de razoabilidade, racionalidade e decência.

Assim, seguindo o caminho de Kant, assume a existência de quatro fatos extraídos da experiência histórica e política, os quais "não foram descobertos pela teoria social, nem devem estar sob disputa, uma vez que são quase truísmos" (RAWLS, 2002, p. 124, tradução nossa). São eles: (i) o fato do pluralismo razoável: a pluralidade de doutrinas abrangentes e razoáveis é a consequência da razão humana sob instituições livres; (ii) o fato da unidade democrática na diversidade: a unidade social e política de uma democracia não exige que os cidadãos endossem uma doutrina abrangente única; (iii) o fato da razão pública: em uma democracia, os cidadãos percebem que não podem chegar a um acordo público com base em razões amparadas em suas próprias concepções; e (iv) o fato da paz democrática e liberal: democracias liberais bem ordenadas não guerreiam entre si.

Tais fatos desempenham um papel semelhante ao fato da razão em Kant, no sentido de que a partir deles é possível empreender uma defesa da fé razoável, isto é, a partir deles é possível se pensar que ordem natural e social não é avessa a um reino dos fins políticos, mas talvez até mesmo conducente a ele:

Podemos agora dizer, como Kant disse, que a organização política de um reino dos fins será uma sociedade (ou confederação) internacional pacífica de povos, cada povo organizado como um estado com algum tipo de regime representativo constitucional. Assumimos que esses regimes sejam estados 
liberais constitucionais ou democracias sociais; para nosso propósito, não importa qual. Assim, quando o reino dos fins é o objeto da lei moral, a fé política razoável é, digamos, a fé em que uma tal sociedade internacional pacífica de povos é possível e favorecida pelas forças da natureza. (RAWLS, 2005, p. 367)

Portanto, o que Rawls faz ao empreender a construção de uma utopia realista é, precisamente, demonstrar a possibilidade do Direito dos Povos em face de nossa condição natural e social: construção de uma utopia realista é a defesa da fé razoável política.

E diz-se razoável porque o Direito dos Povos tem de satisfazer o critério de reciprocidade, o qual implica que um povo deve sempre propor termos de cooperação os quais acredita que os demais possam aceitar. Implica, assim, o reconhecimento do fato do pluralismo razoável a partir de cada doutrina abrangente. Do contrário, tem-se o fundamentalismo ou um relativismo levado às últimas consequências.

Portanto, a recusa de determinados Estados e sociedades a assumir termos de cooperação, os quais é não só razoável, mas racional que aceitem, enseja a intervenção, no sentido de levá-los a transformar suas instituições políticas. Nesse sentido, uma intervenção não pode ser taxada de ocidental ou etnocêntrica, pois não se pode argumentar que a simples ideia da cooperação entre povos é uma ideia ocidental, muitos menos etnocêntrica:

À objeção de que proceder assim é etnocêntrico ou meramente ocidental a resposta é: não, não necessariamente. Isso dependerá do conteúdo do Direito dos Povos que as sociedades liberais vão adotar. A objetividade desse direito claramente não depende em seu tempo, lugar ou cultura de origem, mas se ele satisfaz ao critério de reciprocidade e pertence à razão pública da Sociedade de Povos liberais e decentes. (RAWLS, 2002, p. 121, tradução nossa)

A defesa da fé razoável apresenta a possibilidade de um mundo inteligível e realizável que persegue interesses fundamentais dos povos, e assim da humanidade como um todo, sob a ideia de foedus pacificum e considerando o fato do pluralismo razoável (o que Kant não considerava).

Portanto, não é aceitável, do ponto de vista do Direito dos Povos, que Estados fora-da-lei causem graves violações a direitos humanos, sob a justificativa de que um tal mundo é impossível ou de que está agindo segundo sua própria concepção de bem, compatível com a religião oficial reconhecida, por exemplo. Também não é dado às sociedades oneradas por condições desfavoráveis que recusem a assistência dos povos liberais e decentes, por considerar que isso exigiria a implementação de padrões culturais, políticos ou sociais inaceitáveis para eles. 
Não é legítimo porque tais considerações vão de encontro à crença de que um mundo no qual impere a paz e a cooperação entre os povos razoáveis e decentes seja possível. Pois podemos sempre crer na sua existência, do ponto de vista prático, visto que não há qualquer prova expressa da razão teórica em sentido contrário, o que é suficiente para pressupor sua possibilidade.

\section{Conclusão}

Rawls assume a defesa da fé razoável, de inspiração kantiana, como o papel de sua filosofia política, que, em $O$ Direito dos Povos, assume o sentido de demonstrar que o propósito de paz e cooperação é viável, quando tomados os homens como eles são e as leis como elas podem ser. Assim, passa a elaborar seu projeto de uma utopia realista, a fim de demonstrar a possibilidade de um mundo em que povos liberais e decentes vivam sob o Direito dos Povos. Nesse caminho, há que sempre se tomar precauções para que a proposta seja razoável e racional, o que é feito, sobretudo, por intermédio do critério da reciprocidade e da posição original.

Haverá Estados fora-da-lei que se recusam a cumprir um padrão mínimo previsto pelo Direito dos Povos sob o argumento de que este alberga um mundo fragmentado de falsas doutrinas. É possível também que sociedades oneradas recusem a assistência com base em argumentos relativistas ou fundamentalistas. Pois, como não é possível apresentar uma argumentação sempre convincente, tais tendências seguem os propósitos adotados por cada um deles, ou pelo menos por seus governantes.

Não sendo possível, então, uma dedução da razão prática, a própria razão julga a si mesma, e cabe, então, a nós decidir se é razoável um tal Direito dos Povos. Em caso afirmativo, temos o direito de intervir naqueles Estados e sociedades que fecham os olhos ao fato do pluralismo razoável, ameaçando, por razões que nem todos podem aceitar, a paz e a cooperação internacionais.

\section{REFERÊNCIAS}

AUDARD, Catherine. John Rawls. Trowbrigde: Cromwell Press, 2007. Normes internacionales de justice et globasilation de l'éthique. Veritas - Revista Quadrimestral de Filosofia da PUCRS. Porto Alegre, v. 50, n. 1, p. 23-29, mar. 2005.

KANT, Immanuel. Crítica da razão pura. 5. ed. Tradução de Manuela Pinto dos Santos e Alexandre Fradique Morujão. Lisboa: Fundação Calouste Gulbenkian, 2001. 
. Fundamentação da metafísica dos costumes. In: Textos Selecionados. Trad. Paulo Quintela. São Paulo: Abril Cultural, 1980.

. Para a paz perpétua. Tradução de Bárbara Kristensen. Rianxo: Instituto Galego de Segurança Internacional e da Paz, 2006.

RAWLS, John. A theory of jusice. Rev. ed. Cambridge: Harvard University Press, 1999.

Harvard University Press. 2001.

. Collected papers. Edited by Samuel Freeman. Cambridge:

História da filosofia moral. Tradução de Ana Aguiar Cotrim. São Paulo: Martins Fontes, 2005.

. O liberalismo político. 2. ed. Tradução de Dinah de Abreu Azevedo. São Paulo: Ática, 2000.

. The law of peoples; with, the idea of public reason revisited. 4th ed. Cambridge: Harvard University Press, 2002.

THE RIGHT TO INTERVENTION IN THE REALM OF INTERNATIONAL RELATIONS: THE RATIONAL JUSTIFICATION ACCORDING TO JOHN RAWLS'S POLITICAL PHILOSOPHY

Abstract: The sovereignty, as a characteristic of states' power, has been questioned in the name of norms of international justice. In this context, the right to intervention, possibly based on those norms, appears as a way to compel some societies to acquire preponderant political and social patterns. Thus, this work aims to understand how John Rawls rationally justifies his right to intervention, taken as the right to implement some minimum political and social pattern, even though out of a liberal conception of political justice.

Keywords: John Rawls. Right to intervention. Rational justification

Data de recebimento: jan/2011 - Data de aprovação: mar/2011 